\title{
A IGUALDADE DE OPORTUNIDADES EDUCATIVAS COMO PRESSUPOSTO DA DEMOCRACIA E AS CONTRADIÇÕES NA GESTÃO DEMOCRÁTICA
}

\author{
IGUALDAD DE OPORTUNIDADES EDUCATIVAS COMO UN ASUNTO DE \\ DEMOCRACIA Y CONTRADICIONES EN LA GESTIÓN DEMOCRÁTICA
}

\author{
EQUALITY OF EDUCATIONAL OPPORTUNITIES AS DEMOCRACY ASSUMPTION \\ AND THE CONFLICTS IN DEMOCRATIC MANAGEMENT
}

\author{
Alberto Bive DOMINGOS ${ }^{1}$ \\ Sueli Menezes PEREIRA ${ }^{2}$
}

RESUMO: Pela importância que assume nos tempos atuais a gestão da escola, a pesquisa discute a democracia na perspectiva de uma gestão democrática nas instituições de ensino. Para tanto, o artigo reflete os ideários de igualdade de oportunidades, liberdades, direitos humanos e sociais, defendidos pela democracia moderna, que tem sido palco de contradições na perpetuação de desigualdade e violências sociais em educação, o que implica em analisar democracia no contexto capitalista. É uma pesquisa de cunho qualitativo, do tipo exploratório-bibliográfica. Vale-se da análise documental de publicações relacionadas à literatura inerente às políticas educativas, à democracia, à gestão democrática. Constata que a gestão democrática tem oscilado entre uma gestão paritária do Conselho de Escola e uma gestão discricionária, burocrática, permeável a lógicas mais perversas de controle e hierarquia do que à auto-organização da escola que identifique uma democracia participativa.

PALAVRAS-CHAVE: Igualdade. Educação. Democracia participativa. Gestão. Direitos sociais.

RESUMEN: Debido a la importancia que asume hoy la gestión escolar, la investigación discute la democracia desde la perspectiva de la gestión democratica en las intituiciones educativas. Con este fin, el articulo refleja las ideas de igualdad de oportunidades, libertades, derechos humanos y sociales defendidos por la democracia moderna, que ha sido escenario de contradicciones en la perpetuación de la desigualdade y la violência social en la educación, lo que implica analizar la democracia en el contexto capitalista. Es una investigación cualitativa exploratoria-bibliografica, que utiliza el análises documental de publicaciones relacionadas con la literatura inherente a las políticas educativas, la democracia, la gestión democrática. Señala que la gestión democrática ha oscilado entre la gestión equitativa del Consejo Escolar y uma gestión discrecional y burocrática que impregna lógicas más perversas de control y jerarquia que la autorganización de la escuela que identifica uma democracia participativa.

\footnotetext{
${ }^{1}$ Universidade Licungo (UNILICUNGO), Quelimane - Moçambique. Docente no curso de Administração e Gestão da Educação. Doutorado em Educação (UNESP). ORCID: https://orcid.org/0000-0002-3169-2172. Email: bivedomingos@yahoo.com.br

${ }^{2}$ Universidade Federal de Santa Maria (UFSM), Santa Maria - RS - Brasil. Professora Associada Aposentada e Pesquisadora da área de Políticas Públicas e Gestão da Educação. Doutorado em Educação (UNICAMP). ORCID: https://orcid.org/0000-0003-0831-7494. E-mail: sueli.ufsm@gmail.com
} 
PALABRAS CLAVE: Igualdad. Educación. Democracia participativa. Gestión. Derechos sociales.

ABSTRACT: Given the important role that school management currently plays, this paper aims to discuss democracy from democratic management perspective in educational institutions. Thus, it focuses on ideas of equal opportunity, liberties, human and social rights, which are safeguarded by modern democracy, where conflicts in the perpetuation of inequalities and social violence in education occur, prompting the analysis of democracy in the capitalist context. This is an exploratory-bibliographical, qualitative research that is based on documental analysis of publications that are related to literature pertinent to educational policies, democracy, and democratic management. The study found that the democratic management has oscillated between equal management of the School Council and a management that is discretional, bureaucratic, and that is more tolerant to the perverse logics of control and hierarchy than to the school self-organization which should identify with a participatory democracy.

KEYWORDS: Equality. Education. Participatory democracy. Management. Social rights.

\section{Introdução}

$\mathrm{O}$ artigo retoma os debates clássicos sobre a polêmica da igualdade associada às oportunidades educativas na relação com a democracia participativa e as perspectivas relativas à gestão democrática na concretização dos direitos políticos e sociais. Sustenta uma prática política e pedagógica em que a gestão toma uma posição bastante estrutural, entre outras, abrindo as portas da escola para a comunidade, para que, em conjunto com as autoridades educativas, os profissionais tomem decisões sobre assuntos de natureza pedagógica e administrativa em conformidade com o local onde se insere a instituição de ensino.

A partir de um estudo bibliográfico e documental, enfatiza a gestão democrática da escola, exigência constitucional de um Estado de direito democrático moderno no qual juridicamente impera a separação de poderes, propondo a autonomia como princípio que estabelece a prestação de contas dos profissionais, quer para o Estado, quer para a sociedade em um diálogo baseado na descentralização de competências para o cumprimento dos normativos de educação para a democracia e da educação para todos.

Observa-se, em um exame da realidade educacional, que as configurações atuais dos Estados apontam que desde a década de 1980 diferentes países acentuam as suas políticas em uma mudança no papel do Estado nos processos de política e na gestão escolar. Trata-se do princípio da racionalidade, o que em parte, dificulta a livre iniciativa das comunidades 
educativas nos aspectos sobre a qualidade de ensino, sobre a aprendizagem dos estudantes, o atendimento diferenciado dos alunos, a formação e o conceito de gestão escolar.

De antemão, a relação entre educação e participação envolve a distribuição da renda e fatores como classe social, inteligência, área de residência, educação dos pais, para além de considerações gerais, tais como a efetivação dos direitos sociais, econômicos e políticos, bem como a igualdade de oportunidades constitui um instrumento de requalificação dos jovens em diversas matérias diante da crescente demanda populacional. Porém, a educação é um direito de responsabilização social, um valor em si mesma, de prática que precede a outros direitos sociais e é intrínseca à dignidade humana que, sociologicamente, pressupõe ser considerada ato de cidadania, que não vise apenas maximizar o consumo material.

Indica, também, que a cidadania constitui o árbitro do contrato burguês, em que a igualdade de oportunidades educativas estabelece fonte de inovação nacional em benefício do desenvolvimento de recursos humanos no combate à pobreza com base em recursos locais, exercida de múltiplas formas.

Deste modo, a cidadania dá oportunidades à população e jovens de progredirem com a educação como uma política afirmativa de enquadramento através da educação dos mais carenciados. Promove os recursos humanos num país dependente onde, segundo Souza (2009, p. 53), “[...] os milhões que fracassam respondem pelo seu fracasso, que é sempre individual e de uma classe".

\section{Bases conceituais para análise da igualdade de oportunidades educativas}

A questão da igualdade de oportunidades no sistema educativo tornou-se um princípio constitucional de respeito aos direitos humanos ${ }^{3}$ de um Estado de Direito Democrático ${ }^{4}$, onde o poder, a autoridade, a obediência, a legitimidade, a representação e a participação são

\footnotetext{
${ }^{3}$ Tomando como exemplo, a questão dos direitos humanos, o Estado moçambicano por meio de Resoluções n $^{\circ}$ 8/88 de 25 de agosto; $5 / 91$ de 12 de dezembro; 6/91 de 12 de dezembro e 4/93 de 2 de junho ratificou as seguintes matérias em termos de garantia dos direitos humanos: 1. A carta africana dos direitos humanos e dos povos; 2. O pacto internacional sobre direitos civis e políticos, adotado pela assembleia geral das Nações Unidas em 16 de dezembro de 1966; 3. O segundo protocolo adicional sobre os direitos civis e políticos com vista à abolição da pena de morte; e, 4. A convenção sobre a eliminação de todas as formas de discriminação contra as mulheres (MOÇAMBIQUE, 1988; 1991a; 1991b; 1993).

${ }^{4}$ Em nosso entendimento, o Estado Democrático é aquele que, inspirado na ideologia liberal clássica, desenvolve a democracia e os direitos de liberdade, sendo que há: a) submissão ao império da ? ' lei; b) divisão de poderes; c) enunciado e garantia dos direitos individuais. Nos termos da lei, encontra seu reconhecimento no Artigo 3 da Constituição da República de Moçambique de 2004, ao basear-se no "[...] pluralismo de expressão, na organização política democrática, respeito e garantia dos direitos e liberdades fundamentais" (MOÇAMBIQUE, 2005, p. 2).
} 
instrumentos essenciais na demanda pedagógica e mecanismo de concretização dos objetivos da gestão democrática.

Por volta dos anos de 1980 e sobretudo, a partir dos anos de 1990, incidiu na política global um novo capitalismo de "desmobilização política" (ALONSO, 2009, p. 50), com proporções inquietantes na mudança social no que se refere ao papel do Estado no provimento de direitos fundamentais e, sobretudo, do conceito de cidadania.

Essa política embasou as reformas do Estado modeladas pela Inglaterra, de Margareth Thatcher e pelos Estados Unidos, de Ronald Reagan, entre final dos anos de 1980 e princípio dos anos 1990 do século XX, denominações conhecidas como reformas neoliberais que, entre outras categorias de funcionamento preconizam, sobretudo, a diminuição do papel do Estado, desregulamentação da economia, combate ao sindicalismo, privatizações e redução dos gastos públicos nas políticas sociais.

Neste contexto, a gestão democrática se constitui como uma conquista da cidadania e nela se inferem efeitos políticos, sociais e culturais, focos importantes de poder para a democratização da sociedade, não apenas "no plano das leis, mas dos costumes" (ALONSO, 2009, p. 61). Assim, podemos reconhecer que as relações entre a justiça e o Estado são complexas uma vez que para a proteção dos direitos sociais exige-se legitimidade. Isto é, a soberania popular para a manutenção da dignidade da pessoa na governança difere da avaliação burocrática onde o chefe avalia segundo a sua vontade.

$\mathrm{Na}$ ótica da justiça social na educação, protegem-se as classes desfavorecidas, ponderadas por políticas públicas de ações afirmativas sobre o bem-estar social. Aliás, importa relembrar que, com o neoliberalismo, há perda de soberania pela ineficácia das políticas públicas, pela submissão ao poder econômico e pela ideia da igualdade formal, alienando estrategicamente a sociedade.

Nesta perspectiva, a dignidade das pessoas é rejeitada pela iniciativa economicista da empresa privada para enfrentar cortes financeiros e o Estado se reduz a alguns serviços mínimos, tais como, a segurança pública, a educação, a saúde, a construção e a manutenção de infra-estruturas sociais básicas, entre outras.

No caminho da legitimidade temos a dizer que, na atualidade, não é tão fácil situar as discussões sobre o surgimento da democracia, pois as várias presunções tomadas pelo neoliberalismo não dão sequer uma história exata, remetendo-nos à representação parlamentar e ao liberalismo clássico. Seja como for, há que se destacar as magníficas realizações da cultura grega, sobretudo a ateniense no século V a.C nas cidades-estados gregas que davam muita ênfase à liberdade individual e estimulavam o pensamento criativo. Ainda na Grécia 
descobriu-se a política como uma atividade e arte de decidir através das assembleias, ou discussão pública, e a crença de obedecer às decisões como condição para a preservação social, o que se tornou intelectualmente mais fecundo e com muita relevância na atualidade (BOBBIO, 2000; WOOD, 2005).

De acordo com interpretações históricas naquela época embrionária do debate político, a concepção política do Estado mais avançada foi levada pelos democratas em 594 a.C., isto é, os atenienses com um novo estadista, Sólon, reformaram a constituição da cidade. Há que salientar que este estadista deu um contributo extremamente importante do que se destaca o fim da prática de escravizar devedores, assim como a libertação de muitos escravos. Dividiu os cidadãos em quatro classes, de acordo com a riqueza, onde cada classe tinha o direito de servir em determinado nível de governo, ou de eleger autoridades. Porém, um outro estadista, Clístenes, em seu governo "deu a todos os cidadãos do sexo masculino o direito de trabalhar no governo e votar em decisões importantes" (WOOLF, 2014).

Neste contexto, a

Cidadania ativa seria reservada para os homens proprietários e deveria excluir não apenas as mulheres, mas também os homens que, [...] não tivessem 'com que viver por si só' - ou seja, aqueles cuja sobrevivência dependesse do trabalho prestado a outros. Essa concepção de cidadania tinha em seu núcleo uma divisão entre uma elite proprietária e uma multidão trabalhadora (WOOD, 2005, p. 179).

Embora as reformas políticas implementadas não tivessem o agrado da maioria, ou seja, fossem contestadas, não deixam de se inscrever nos anais da história política da humanidade, constituindo bases do primeiro governo, humanamente democrático do mundo que vigorou em 508 a.C.

Deste modo, é extremamente importante trazer a cronologia conceitual da democracia que perdurou na Antiga Grécia, considerado o pivô intelectual original da Democracia. Destarte, o termo é, porém, certamente gregário de dois sentidos:

i) a palavra Poder, ou governo, subentendendo-se que autocracia é o governo de um só homem; aristocracia, governo dos aristoi, os melhores, a elite; sendo a democracia governo pelo demos, o povo; e, ii)a palavra Demos que é também uma palavra versátil com diversos significados; entre eles, o de povo como um todo (ou o corpo de cidadãos) e as pessoas comuns (ou as classes mais baixas) (FINLEY, 1988, p. 25-26, grifos do autor).

Ao se associar o termo democracia às classes mais baixas da sociedade impõem-se ao Estado a obrigação de oferecimento de condições aos indivíduos para o aprimoramento das suas capacidades, quer na ciência e na tecnologia, quer nos benefícios econômicos e na 
cultura através da educação. De forma contrária, "representam instrumentos impeditivos, tanto da autonomia profissional dos docentes, como da autonomia pedagógica das escolas com seus reflexos na organização escolar como um todo" (PEREIRA, 2009, p. 78).

Assim, o verdadeiro sentido da democracia burguesa nos remete ao reconhecimento de que:

A tirania é a monarquia governando despoticamente a comunidade política; existe oligarquia quando o controle do governo está nas mãos dos possuidores de riquezas; democracia quando, ao contrário, o poder é exercido pelos que não possuem muitos bens, ou seja, pelos pobres (ARISTÓTELES, 1997, p. 92).

Neste sentido, percorrem vários instrumentos visando aprimorar a igualdade de oportunidades educativas na relação do Estado e democracia: o sufrágio universal, ou voto popular, a existência de constituições que assegurem os direitos e as garantias individuais dos cidadãos, limitações da atuação do Estado e a incidência na separação dos poderes Legislativo, Executivo e Judiciário, de onde derivam consequências jurídicas.

Desta maneira, o princípio do Estado social democrático insere-se na minimização dos conflitos de interesse entre grupos, num tripé, Estado capitalista, Trabalho e Democracia, para a prevalência do funcionamento eficaz do Capitalismo, ou seja, numa conjugação combinada entre equidade com a racionalidade econômica, bem como, entre a democracia com o capitalismo e a igualdade com a liberdade.

Quer dizer, por um lado, o Estado concilia as reivindicações populares e, por outro lado, deve atender às exigências do capital, o que gera uma crise de legitimidade.

A Revolução Francesa conseguiu difundir pelo mundo seus ideais que permanecem até os dias atuais como bases das democracias modernas.

Todavia, com Napoleão na França remanesceram os direitos políticos civis e sociais. No seu reinado fundou escolas públicas e laicizou o ensino básico e implementou a escola francesa de ensino normal para preparação dos professores na sua função e criou o Código Civil francês. Desenvolveu políticas públicas que impulsionaram o desenvolvimento tecnológico pela indústria e comércio franceses. O governo de Napoleão também ratificou a redistribuição de terras promovida pela Revolução e reformulou o sistema bancário, criando uma moeda nacional com o intuito único de exercer maior controle nas receitas fiscais-

No entanto, embora as leis constitucionais imponham a noção de igualdade formal entre as pessoas, há coexistência de relações baseadas nos privilégios hereditários ou outros favorecimentos. Algo a destacar é, se as constituições liberais reconhecem a garantia da 
educação pública pelo Estado, que entre outras exigências tem de promover a gestão democrática do ensino público, significa que o poder emana do povo, que o exerce por meio de representantes eleitos ou diretamente.

Deste modo, os normativos que configuram a gestão democrática constituem mecanismos públicos de ordem jurídica e política, consequentemente, os dois pilares da democracia: a representativa participativa (indireta) e a democracia participativa (direta). E entendendo a igualdade de oportunidades escolares como a participação social e popular no desenvolvimento da cidadania pela educação, trata-se de um direito de todos e dever do Estado e da família como princípio inerente à democracia.

Assim, na correlação entre democracia, igualdade de oportunidades e oferecimento da educação e, ainda, a provisão de direitos, a gestão democrática visa o pleno desenvolvimento da pessoa, seu preparo para o exercício da cidadania e sua qualificação para o trabalho. E, ainda, os pobres e outros carenciados passam também a fazer parte das soluções de suas condições, sobejamente indesejáveis. Aliás, a exclusão e o fracasso escolar são imputados à ausência de habilidades e capacidades dos alunos e suas famílias, igualmente ao mau desempenho da escola e logicamente dos seus profissionais.

Trata-se do gerencialismo que afeta as organizações. Sabe-se que o seu apanágio é o modelo privado em que nele o mercado autorregula-se, ou seja, dita leis com base na harmonia entre o individualismo e a economia. E, em consequência, a reforma administrativa do Estado consolida mais burocraticamente o Estado centralista. Isto é, "o poder do Estado moderno não passa de um comitê que administra os negócios comuns da classe burguesa como um todo" (MARX; ENGELS, 2010, p. 87).

No âmbito de um Estado neoliberal as denominações de bem comum, igualdade e de justiça regridem substantivamente, pois são colocados interesses mercadológicos mais expansivos sobre a dignidade humana, em que a justiça se modifica na liberdade de troca através da cidadania, tornando o cidadão mais interventivo nos seus direitos ou necessidades.

Neste contexto, na lógica de recomposição da hegemonia capitalista e das relações capital-trabalho, o papel do Estado é colocar a liberdade de todas as privações no epicentro das iniciativas e jogar um papel de suporte e salvaguarda de capacidades humanas e não constituir sistemas de provimento de serviços prontos para o consumo.

Isto é, embora socialmente, o governo use medidas de discriminação positiva (como bolsas de estudo, fornecimento de residências estudantis, material gratuito, entre outras), ao invés da igualdade no acesso, desempenho e tratamento para todos, evidencia-se a equidade. Aí a escola reproduz internamente relações de poder em relação às classes populares e contra 
a participação na tomada de decisões sobre a gestão escolar. E a gestão democrática no plano das orientações gerais tornou-se um projeto de regulamentação dos Sistemas Nacionais de Educação, sendo promovida e incentivada com a colaboração da sociedade, isto é, não praticada e construída na prática pelos atores, pois, assim, demandaria o exercício autônomo dos profissionais.

Em contrapartida às vivências totalitárias na escola pública estatal, Dal Ri (2013, s/p), sugere-nos outra perspectiva da pedagogia dos movimentos sociais de trabalho associado, cujos elementos são alternativas confiáveis, humanamente democráticos que, com base na autoeducação, na cooperação e na solidariedade busca-se promover a "organização e gestão democrática das escolas, união do ensino com o trabalho produtivo e transmissão de uma visão de mundo crítica ligada à classe trabalhadora".

Ora, o trabalho como elemento imprescindível para o homem e a sociedade é criativo e forjador, mas na burguesia é alienante e "[...] o capital é autônomo e pessoal, enquanto o indivíduo que trabalha não tem autonomia" (MARX; ENGELS, 2010, p. 102).

Sobre o papel e lugar da sociedade civil importa reconhecer as transformações ocorridas nos meados do século XIX, sobretudo, a Revolução Industrial que deu espaço à expansão dos princípios liberais burgueses que ocasionaram reações difusas tornando-se contraponto ao próprio liberalismo.

Dessas transformações merecem destaque os ideais do socialismo, no qual a proposta alternativa seria alcançada pela ditadura do proletariado através da apropriação dos meios de produção. Nessa perspectiva, Marx nos seus primeiros escritos, manifestou um compromisso profundo com o ideal da democracia direta. Isto é, a concepção inicial desse gênero de democracia prendia-se a uma crítica rousseauniana do princípio da representação e à concepção de que a verdadeira democracia implica o desaparecimento do Estado burguês, desse modo, o fim da separação entre o Estado e a sociedade civil, que ocorreria porque a sociedade passaria também a ser um organismo de interesses homogêneos e solidários e, consequentemente, a esfera política distinta, da esfera do interesse geral, que desapareceria juntamente com a divisão entre classes sociais, ou seja, entre governantes e governados, ou ainda entre planejadores e executores (BOTTOMORE, 2012, p. 143).

Trata-se do "[...] princípio democrático fundado na igualdade econômica e o espaço da liberdade originado das relações intersubjetivas, que formam sempre, as bases caracterizadoras do ideário marxista" (MAGALHAES, 2014, p. 78).

Portanto, os direitos dos indivíduos como cidadãos cedem aos direitos dos indivíduos enquanto consumidores, ou seja, as decisões sobre políticas educativas podem não 
salvaguardar os direitos do mundo cívico, com consequências negativas designadamente ao nível da justiça social e da capacidade de mobilização coletiva dos menos capazes na defesa dos seus interesses.

Os significados primitivos de sociedade civil, nos primórdios da Inglaterra dos séculos XVI e XVII, eram tidos como sinônimos de "sociedade política", ou o Estado visto como a coisa pública. Entretanto, a concepção moderna de sociedade civil que aparece no século XVIII é muito diferente das noções anteriores de sociedade, em decorrência do surgimento de uma economia autônoma, pois é separada da unidade do político e do econômico. Assim,

sociedade civil representa uma esfera diferenciada do Estado, separadas das relações e das atividades humanas, nem pública nem privada, ou talvez as duas coisas ao mesmo tempo, incorporando toda uma gama de interações sociais fora da esfera privada do lar e da esfera do mercado, a arena de produção, distribuição e troca (WOOD, 2005, p. 206).

Na observação de Souza (2009, p. 41), essa distinção faz sentido na medida em que se evidencia o poder público comunitário, na distinção entre o Estado e os movimentos sociais, ou seja, na ruptura com a imagem romântica e ingênua do proletariado, como movimentos que têm por sujeito coletivo a classe que vende sua força de trabalho para sobreviver, o que os diferencia de movimentos identificados como sociais do ponto de vista da classe detentora dos meios de produção.

Nesse contexto, o dualismo Estado e sociedade civil, mais ou menos desapareceu da corrente principal do discurso político. E, segundo Souza (2009, p. 50), “[...] a sociedade civil não pode ser pensada em separado da sociedade política, a não ser que queira mascarar as condições reais da luta de classes". E, em observância ao princípio da ação pública das escolas numa visão política da gestão escolar tomamos em consideração que essa concepção reaparece nos textos de Marx sobre a comuna de Paris.

Onde,

em lugar de decidir uma vez em cada três ou seis anos qual o membro da classe dominante que deverá representar mal o povo no parlamento, o sufrágio universal deveria servir ao povo, constituído em Comunas' $(A$ guerra civil na França) (BOTTOMORE, 2012, p. 143, grifos do autor).

No entanto, a noção de igualdade de oportunidades na vertente democrática da escola vai além das concepções tecnocráticas e da racionalidade fiscal, cobrindo dimensões dialogista, crítica e emancipatória. Contudo, a igualdade nos moldes pós-revolucionários marcianos, de acordo com Bottomore (2012, p. 275), se distinguem em duas perspectivas totalmente antagônicas: 
1) da distribuição, cujo enfoque é cada qual segundo sua capacidade, ou seja, a cada qual segundo o trabalho realizado. E, tendo em conta que, as diferenças nas realizações individuais são, pelo menos em parte, resultado de diferenças de talento e capacidade que são inatas ou produto das condições ambientais, e, como as situações familiares e condições de vida dos diferentes indivíduos são muito diversas (desde diferenças no físico e as correspondentes necessidades de vestuário e alimentação, até as diferentes responsabilidades impostas por diferenças no tamanho da família, etc.), esse princípio de distribuição não equivale ainda a uma igualdade justa (tratamento igual), pois, embora uma igualdade abstrata seja formalmente aplicada a todos os indivíduos, eles recebem na realidade um tratamento materialmente desigual.

2) o princípio de 'cada qual segundo sua capacidade, a cada qual segundo suas necessidades', corresponde à fase comunista superior da sociedade pós-revolucionária. Isto é, apenas no comunismo como forma de Estado dos trabalhadores, seria conferido um tratamento realmente igual aos seres humanos desiguais, com todas as suas necessidades forçosamente desiguais. Isto é, o contraponto básico a tomar em consideração de que é "uma sociedade que assegura meios de vida adequados a todos e na qual já não há hierarquias de poder e de prestígio" (BOTTOMORE, 2012, p. 275).

Os dois argumentos nos moldes da igualdade de oportunidades educativas no direito a educação tendem a ser compreendidos como formar o cidadão para participar nos destinos de seu país, como ator com responsabilidades políticas, sociais e ambientais, ou ecológicas da sociedade moderna, sob o critério da democracia direta na qual a auto-organização escolar é uma necessidade essencial para a melhoria da qualidade da educação.

Isto é, a escola por um lado, define suas políticas educativas e, por outro lado, a organização escolar está intrinsecamente ligada à criação de espaços de deliberação coletiva onde a gestão democrática se dá em dois níveis: do sistema de ensino e das escolas, em particular que se configuram numa das grandes dimensões que possibilitam um maior acesso às finalidades educacionais em que a qualidade de educação e a melhoria do ensino constituem primados do direito universal.

Ainda sobre a democracia na atualidade, um fato notável, tanto na escola pública democrática, quanto à democracia da participação ou direta no sistema educativo resume-se na representação dos profissionais nos órgãos tradicionais da escola, os Conselhos de escolas. Esses, em parte, na prática, nada ou pouco contribuem para o projeto político pedagógico 
deliberativo, isto é, nem favorecem a participação efetiva da comunidade nos assuntos da escola em geral e, em particular, para uma progressiva autonomia pedagógica, administrativa e de gestão financeira para a resolução dos problemas de ensino e da gestão inerentes à melhoria da qualidade da educação, condições inexoráveis para uma educação consciente e critica.

$$
\text { Por isso, no dizer de Bobbio (2000, p. 69), }
$$

Podemos, assim, considerar reforma democrática a que instituiu os conselhos escolares com a participação dos pais. [...]. Inútil esconder que este é um processo apenas iniciado, do qual ainda não estamos em condições de conhecer nem as etapas, nem a duração. [...]. Existem alguns sintomas encorajadores e outros, nem tanto. [...]. A participação multidirecional tem o seu reverso da medalha que é a apatia política. O custo que se deve pagar pelo empenho de alguns poucos é com frequência a indiferença de muitos.

A gênese das contradições de igualdade encontra-se no Liberalismo ${ }^{5}$ como ideologia de pensamento que prima pela autonomia moral, política e econômica da sociedade civil em oposição à concentração do poder político. É nesta ordem de ideias pré-concebidas que o liberalismo ganhou expressão moderna com os seus adeptos intelectualizados como John Locke (1632-1704) e Adam Smith (1723-1790) entre outros.

Assim, entre os seus princípios do reinado da liberdade encontram-se os seus maiores conceitos da performatividade, individualismo, o direito à propriedade privada e o governo limitado. Entre outras, o liberalismo defende ainda a inviolabilidade das liberdades civis e de mercado, condenando a interferência excessiva do Estado na economia. Isto é, na sequência, atualmente, “[...] o modelo neoliberal não consegue promover a fé, a esperança, a solidariedade, a paz ou conceitos como cidadania e equidade social, pois que se lhes são auto excludentes" (GALVÃO et al., 2012, p. 245).

Nesta concepção, com o advento da guerra e outras calamidades mundiais, ou depressões econômicas, crises globais e outros provérbios de sentença da coisa pública, os recursos educacionais não são disponibilizados, pois tendem a diminuir visando o cumprimento desses propósitos perpetrados pelo culto de eficiência, manifesta contenção de despesas públicas. Mas não é só isso que é importante na nossa intenção, pois a democracia moderna ignora a esfera econômica como pertencente à esfera pública, ou seja, "a democracia liberal moderna tem em comum com a antiga democracia grega a dissociação entre a identidade cívica e o status socioeconômico que permite a coexistência da igualdade política formal com a desigualdade de classe" (WOOD, 2005, p. 183).

\footnotetext{
${ }^{5}$ Resumidamente, “[...] o liberalismo é a tradição de pensamento que situa no centro de suas preocupações a liberdade do indivíduo" (LOSURDO, 2006, p. 13).
} 
Desse último ponto de vista, a democracia representativa burguesa favorece cada vez mais as classes proprietárias e traz consigo uma ideia de uma cidadania mais expansiva e inclusiva, mas também, mais abstrata e com conotação de passividade. À semelhança, o poder popular deixa de ser critério principal nos valores democráticos de sociedade livre, justa e solidária que justamente muda trazendo os direitos constitucionais, processuais e a privacidade do cidadão individual.

É perfeitamente compreensível que, sem nenhum sentimento de nacionalismo exacerbado, além-fronteiras, os direitos cívicos evocados são "direitos do Homem egoísta, individualista, motivado apenas pelos seus interesses particulares" (DORNELLES, 2005, p. 132).

Hoje, mais do que ontem, as mesmas questões continuam a colocar-se, "a igualdade pública [...] pouco ou nada representa no espaço real da existência que seria o espaço privado, ou o mercado, onde na prática se reproduziriam as diferenças, as desigualdades, a opressão e a exploração, com base nessas diferenças" (DORNELLES, 2005, p. 132).

Este engajamento público nos moldes individualista qualifica um militantismo de educação que neutraliza os valores humanos e secundariza o social na política educativa, dedicando-se apenas à educação tecnocrática ou autoritária, fio insuficiente para evocar a gestão democrática da escola, pois foi demonstrado anteriormente que uma educação de participação humana e popular, deve ser coerente com uma concepção de democracia que emancipa através da educação pela sua organização.

Sem prejuízo da lógica quantitativa na educação e em detrimento da ação humana, a participação é um elemento chave no desenvolvimento de políticas públicas, isto é, na sua elaboração e implementação, pois constitui-se como um mecanismo de controle social de formas de organização, fiscalização, assim como para o exercício e aperfeiçoamento do diálogo e de uma relação mais democrática institucional entre a atuação de gestores públicos e os cidadãos, em nome da sociedade civil.

Daí o círculo vicioso como aponta Macpherson (1978, p. 103):

Não podemos conseguir mais participação democrática sem uma mudança prévia da desigualdade social e sua consciência, mas não podemos conseguir mudanças da desigualdade social e na consciência sem um aumento antes da participação democrática.

Assim, os espaços de participação seriam constituídos por ambientes formais e informais manifestando-se em conferências, tais como conselhos escolares, ouvidorias, 
audiências públicas, em consultas públicas e promoção de colegiados frouxamente hierarquizados, abertos e flexíveis considerados campos de monitoria da ação governamental.

$\mathrm{Na}$ teoria da participação trata-se de um complemento entre as democracias direta e a representativa, fenômenos que fortalecem a igualdade formal, sobretudo a jurídica que não é substantiva, dado que ela é insuficiente sem a igualdade econômica, mas compensatoriamente aproximando o cidadão do Estado. E em termos de liberdades, civil, de expressão, de imprensa e de reunião, promove a tolerância, a defesa do indivíduo e da sociedade civil contra o Estado, mas deixa também, intocada, uma nova esfera de dominação e coação criada pelo capitalismo, com a separação e isolamento da esfera econômica e sua invulnerabilidade ao poder democrático.

O capitalismo é constituído da exploração de classe, submetendo toda vida social às exigências do mercado, através do trabalho, lazer, consumo, organização do tempo. As bandeiras sobre a gestão democrática levantadas em causas próprias de democracia participativa ou de pequenos grupos como os conselhos de escola trazem o enfraquecimento da luta das classes, transvestida em um discurso sobre a autonomia, a liberdade de escolha e autogoverno democrático.

Com esse propósito, o capital assumiu o controle privado sobre questões do domínio público, ao mesmo tempo em que transfere para o Estado responsabilidades sociais e políticas. Portanto, as identidades que surgiram com o advento pós-moderno não diluem as desigualdades ou diferenças extra econômicas, políticas ou jurídicas. Assim, a extração da mais-valia dos trabalhadores assalariados acontece numa relação entre indivíduos formalmente iguais e livres, pois, como ficou exposto anteriormente, o capitalismo não promove a liberdade para a paz mundial, pelo contrário se utiliza das identidades múltiplas, das questões raciais, das questões ecológicas e de gênero para maior exploração humana.

A este propósito, os autores do Manifesto Comunista entendiam o Estado moderno como o executivo que nada mais é do que "um comitê que administra os negócios comuns da classe burguesa como um todo" (MARX; ENGELS, 2010, p. 87). Significa paradigmaticamente, que a história do capitalismo fez brotar a segregação social, as desigualdades sociais e os racismos de várias origens. Isto é, as condições de trabalho e de vida, no capitalismo, são privilégios de uns poucos brilhantes. E com a estagnação do declínio da taxa do analfabetismo, não garantem a justiça social, pois persiste o problema da má distribuição da riqueza e a falta de participação política dos cidadãos, fatos que afetam os sistemas de ensino. 
Entretanto, as formas envelhecidas mais independentes de participação no tecido social consistiriam em formas autônomas de organização, gestão e de atuação política dos grupos, nas classes populares e trabalhadoras e, ainda de grupos sindicais que se constituiriam em movimentos sociais e em associações de moradores. Promoveriam lutas sindicais, marchas e lutas comunitárias (manifestações, ou reivindicações por melhores condições trabalhistas e não apenas salariais), isto é, fazer dialogar, no interesse das políticas públicas emancipatórias. Esta é a forma de democracia direta fazendo frente à participação formal regulada externamente, por meio de imposições, cooptação, subordinação, fragmentação e dissolução das lutas populares.

Naturalmente,

para que exista democracia direta no sentido próprio da palavra, isto é, no sentido em que direto quer dizer que o indivíduo participa ele mesmo nas deliberações que lhe dizem respeito, é preciso que entre os indivíduos deliberantes e a deliberação que lhes diz respeito não exista nenhum intermediário (BOBBIO, 2000, p. 62).

Esta citação traduz a ideia de que a gestão democrática nega a despolitização da educação e da escola, e ainda, da sociedade e dos cidadãos causada pela ideologia da competência, da meritocracia e da performatividade que separa dirigentes e executores. Quer dizer que, no fundo, trata-se de um ato político da participação em si, e da autonomia no sistema educativo que, entre outras formas, preconiza a eleição de diretores de escola, a constituição de conselhos de escolas com um funcionamento mais democrático sobre a gestão, em que devem participar todos os segmentos escolares: pais, professores, alunos, funcionários e toda a comunidade educativa.

Em resumo, este episódio cultural da pedagogia política sobre os oprimidos contribui para o Planejamento participativo através da construção do Projeto Político-Pedagógico, no qual são discutidas prioridades da gestão escolar, informação sobre recursos públicos disponíveis para, finalmente, elencar critérios de distribuição e execução orçamentária, como contrapontos da pedagogia do opressor.

Dado que a democracia e capitalismo não são compatíveis, o sistema capitalista é um terreno de dominação e coação, que torna "os cidadãos sem direitos, os trabalhadores e trabalhadoras tornam-se em grande medida, súditos de um poder que é exercido pelas múltiplas redes da racionalidade capitalista" (SOUZA, 2009, p. 53).

Deste modo, a categoria econômica precisa ser repensada, dado que o capitalismo humano, verdadeiramente democrático justo e igualitário é impossível em um sistema capitalista e se torna absolutamente mais utópico que no socialismo (WOOD, 2005). O 
socialismo, por si, pode não ser uma gama de garantias de completa conquista dos bens extra econômicos, talvez não resolva os problemas dos racismos, da exploração feminina, mas ele permitirá a revalorização dos bens extra econômicos, cujo valor foi deteriorado pela economia capitalista (WOOD, 2005), seguramente, constituindo em uma alternativa de administração equilibrada, pois como foi descrito, a igualdade política legal e formal, ou seja, de oportunidades, no sistema capitalista, acomoda as desigualdades de classe.

\section{As contradições relativas à gestão democrática e direitos sociais}

As contradições relativas à gestão democrática e direitos sociais são desencadeadas pela natureza do sistema político nas tendências de gerência sendo que há variações nas definições que poderiam ser consideradas qualitativas:

A-em relação a fatores biológicos dos seres, raça, cultura dos diferentes elementos da população,

B-os fatores geográfico e do meio ambiente, ou modificações ecológicas e de localizações das escolas.

Em todo caso, a cultura revela-se como diretriz de mudança social de certas tendências. E as escolas como instâncias sociais e de poder não existem apenas como intermediárias da herança cultural de uma sociedade e das transformações mecanicistas impostas pela crise fiscal dos Estados, existem também para ajudar na perpetuação e promoção da mudança e reforma social.

Aqui, a descentralização e o planejamento local constituem mecanismos administrativos de participação popular sobre a defasagem cultural das autoridades em relação à aprendizagem dos alunos. A participação em si, traz inúmeras vantagens em relação ao modo como a educação é percebida como responsabilidade familiar e socialmente coletiva, pois indica como os professores são preparados para a profissão, traduzindo-se em uma educação social que se preocupa com o desenvolvimento da capacidade mental, lúdica, estética e ética do aluno e, entre outras, não se limita apenas a cumprir objetivos mercadológicos de recompensas externas, que se cingem na avaliação externa, que caminham para a mobilização de interesses contábeis, tais como, notas, prêmios, classificações, no dever dos pais sobre as questões educativas em relação aos direitos e liberdades de escolher o tipo de educação e de escola a serem seguidas. 
Uma educação de igualdade de acesso e sucesso dos alunos que promovam a democracia e o desenvolvimento implicam mecanismos compensatórios de trabalho com a diferença, no atendimento ao aluno real e não apenas ao ideal, isto é, que dê mais aos que menos têm. Inequivocamente, traduz-se numa gestão em que os atores são participativos.

As comunidades educativas, professores, alunos, pais e a comunidade em geral se envolvem, de forma democrática, na definição das prioridades da escola, cujo enfoque é a gestão financeira como fonte de aplicação dos recursos da e sobre a escola. Ademais, a democracia, a justiça e o desenvolvimento pessoal no sistema educativo necessitam de um sistema flexível e inclusivo, mais centrado nos alunos e no seu trabalho, menos nas classificações tópicas e hierárquicas, que permitem diferentes percursos, enquanto promovem a integração interclassista e intercultural como objetivo último da escola democrática e justa.

Contudo, o estabelecimento dos sistemas educacionais e às escolas no sistema capitalista de inspiração burguesa persegue interesses capitalistas de consolidação de ideais e performances de dominação. As práticas educativas, nem sempre são conscientes por parte dos atores da escola. Mas, em todos os casos, as opções políticas, organizacionais e mesmo teórico-metodológicas da gestão da escola e da sala de aula, muitas vezes, legitimam e consolidam as desigualdades sociais, não garantindo o direito, previsto legalmente na Constituição de uma educação democrática, igual e de qualidade para todos. Outra contradição quanto ao estabelecimento dos normativos constitucionais e que interessa reter, o subsidio dado por Losurdo (2006, p. 18), de que “[...] toda lei é feita pelos seus donos, os quais nunca vão deixar passar uma medida desfavorável a eles"”.

Nesses termos vale anotar a contribuição que a consciência do direito à educação básica avançou, porém não conseguimos que a escola se estruturasse para garantir esse direito, sendo que ela continua como uma instituição seletiva e excludente na sua organização. Isto é,

O sonho de uma administração racional do público parecia trazer a tão esperada autonomia da escola e de seu administrador. O cargo passaria a ser ocupado por profissionais habilitados e concursados supostamente neutros e apolíticos. Vimos a ingenuidade dessa pretensa apoliticidade da administração do público. Julgamos que continuar sonhando com uma prática de administração escolar apolítica, ocupada por profissionais concursados e habilitados, é gastar esforços numa luta irrealista, baseada em uma visão ingénua da sociedade, do estado, da escola e de sua própria função (ARROYO, 1992, p. 128).

Sem dúvida, a escola pública nos moldes burgueses é precarizada e mais palpável na ausência de recursos financeiros, que tornam cada vez mais precárias as condições de 
trabalho, com a falta de material didáctico, edifícios, baixa remuneração salarial dos seus profissionais e superlotação nas salas de aulas. Ensina aos alunos os requisitos mínimos da cultura e da democracia, evitando a luta pela superação dessa mesma sociedade. Ela está mais preocupada naquilo que possibilita exercer com perfeição as funções da produção, considerando-se de um local de preparação de recursos humanos para os postos de trabalho existentes na sociedade.

A prática atual das escolas baseia-se no princípio de que a missão das escolas e dos professores é passar, ou seja, "dar a matéria", preconcebida. Isto é, entendida como transmissão de um conjunto prescritivo de conteúdos atípicos, uniformes, descontextualizados e indiscutíveis, sem o respeito à sociedades plurais e em transformação onde impera o respeito pela diferença.

Numa escola justa os currículos escolares seriam mais flexíveis e abertos para atender à democracia e ao desenvolvimento, sem deixar interseção das conjunturas local, nacional e internacional. Suposições e garantia de obtermos cidadãos e trabalhadores participativos, reflexivos, criativos, autônomos comprometidos com a transformação social, denunciando a intolerância, pois nos dizeres de Souza $(2009$, p. 52), “[...] se no início a cidadania pretendiase expansiva, agora ela é necessariamente restritiva".

Dal Ri (2013, s/p), argumenta que a auto-organização dos trabalhadores como sujeitos ativos no controle do processo trabalhista até ao início do século XIX evidenciava que "[...] os profissionais eram os repositórios do conhecimento técnico do processo da produção". Isso em plena alusão à autonomia em que os trabalhadores detinham um significativo poder decisório sobre as opções convenientes e domínio sobre os processos de trabalho.

O autor acrescenta que preservavam a capacidade de admissão de aprendizes e de regular seu progresso profissional, e ainda, aliada à gestão democrática das suas ações e dada a dependência técnica da habilidade dos trabalhadores, eles tinham um grande poder de barganha. Assim, nos moldes políticos, a gestão democrática é, substancialmente, parte integrante do projeto político-pedagógico da escola, como expressão de sua autonomia e de sua identidade própria. Ela democratiza o acesso e sucesso, o saber e as relações além de garantir o sucesso dos alunos, portanto, abrange as vertentes pedagógica, administrativa e financeira. Evoca a participação de todos que compõem a escola na tomada de decisões: diretores, professores, técnicos, funcionários, pais e alunos. Incentiva a perspectiva educativa da democracia, implica consciência da aprendizagem para o exercício participativo e propositivo da cidadania, pois só se aprende democracia, sendo democrático, através de formas de organização, implantação e implementação de estruturas de reflexão e tomada de 
decisão coletivamente, em fóruns de participação comunitários para a escolha dos dirigentes com o predomínio de assembleias gerais da comunidade escolar (conselhos deliberativos escolares, associações de pais, organizações de alunos e professores conscientes voltados para o sucesso do seu trabalho).

Tudo numa perspectiva que visa ao cumprimento da função da escola na socialização dos saberes acumulados historicamente pela humanidade e de formação de valores e atitudes voltados para o exercício pleno da cidadania, tolerância e espírito de compromisso, e ainda, na instituição de mecanismos de circulação e partilha de informações entre os diversos segmentos sociais, com o estímulo a reuniões periódicas, murais e boletins informativos, divulgação de atas e relatórios sobre os esforços alcançados numa gestão humanizada através de um clima de convivência democrática e uma liderança que estimule a participação.

Uma gestão que soluciona criativamente os problemas contribuindo para a geração de consensos internos por meio do diálogo sobre os diferentes posicionamentos. Também, as decisões são tomadas coletivamente e jamais por uma pessoa, ou pequeno grupo de pessoas, é uma gestão fundamentada na participação e ainda na formação de todos os segmentos para a participação, que consiste na formação dos diretores, dos conselhos ou membros das associações para o conhecimento da legislação nacional e local para que não haja inibição da voz dos considerados menos escolarizados sobre questões escolares, como pais, funcionários e alunos.

$\mathrm{Na}$ tomada de decisões devem-se respeitar os processos, evitando a burocratização e rotinização da gestão, que priorizam prazos, normas procedimentais, atas e outros ofícios em detrimento do pensar e do agir coletivos. Isso para que o critério central das decisões coletivas seja o da qualidade da escola pública e não o interesse elitista ou excludente, descomprometido com a educação e não enfatizada na transformação social, princípio básico da igualdade de oportunidades educativas.

\section{Considerações finais}

Ao elegermos o estudo das políticas educacionais, constatamos que ainda há vários embates a serem superados. As promessas de igualdade de oportunidades educativas nos sistemas de ensino estão longe de oferecer uma provisão pública de educação e um ensino de qualidade, traduzindo-se num resultado paradoxal.

O sistema educacional usa uma pequena proporção dos recursos escassos da sociedade, sendo que os investimentos são menores, quer em edifícios e quer em mobiliários escolares, 
infelizmente, menos equipados, simplificando a relação entre a educação, economia e sociedade. Da política de mercadorização da escola nota-se uma crescente fragmentação social, cultural e étnica dos sistemas de ensino e das famílias a que se acresce uma degradação da qualidade e dos resultados processuais dos sistemas educativos.

Embora os direitos sociais estejam consagrados nas Constituições só podem ser assegurados quando tiver uma garantia econômica, por exemplo, um financiamento crescente na educação pública.

A política neoliberal na educação, a sua materialização não alcança a todos, isto porque promove os alunos e professores, os currículos e saberes escolares, como bens comercializáveis, cuja finalidade é o reforço de uma escola (re) produtora e legitimadora da ordem social e das hierarquias sociais pré-definidas em função do status de pertencimento, enfim, pressupondo recursos e mobilização de pessoas e entidades para a sua concretização através da democracia participativa. Porque a igualdade de oportunidades educativas efetiva conduz ao direito à paz, o direito ao desenvolvimento, o direito à autodeterminação dos povos, o direito ao meio ambiente saudável e ecologicamente equilibrado, o direito ao patrimônio comum da humanidade e o direito à informação, princípios basilares formalmente defendidos pela democracia representativa

\section{REFERÊNCIAS}

ALONSO, A. As teorias dos movimentos sociais: um balanço do debate. Revista Lua Nova, São Paulo (SP), v. 76, p. 49-86, 2009.

ARISTÓTELES. Política. Brasília, DF: Editora Universidade de Brasília, 1997.

ARROYO, M. A administração da educação é um problema político. Revista Brasileira de Administração da Educação, Porto Alegre (RS), v. 1, n. 1, p. 122-129, 1992.

BOBBIO, N. O futuro da democracia. São Paulo, SP: Paz e Terra, 2000.

BOTTOMORE, T. Dicionário do pensamento Marxista. Rio de Janeiro, RJ: Zahar, 2012.

DAL RI, N. M. Movimentos sociais e educação democrática: antecedentes da pedagogia do trabalho associado. In: ELISALDE, R. et al. Movimientos sociales, educación popular y trabajo autogestionado en el cono sur. Buenos Aires, Argentina: Buenos Libros, 2013. v. 1, p. $137-164$.

DORNELLES, J. R. W. Sobre os direitos humanos, a cidadania e as práticas democráticas no contexto dos movimentos contra hegemônicos. Revista da Faculdade de Direito de Campos, ano VI, n. 6, p. 121-146, jun. 2005. 
FINLEY, M. I. Democracia antiga e moderna. Rio de Janeiro, RJ: Graal, 1988.

GALVÃO, A. C. T. et al. Desafios da política e governança educacional na promoção da cidadania no Brasil. In: GUIMARAÊS-LOSIF, R. Política e governança educacional. Brasília, DF: Universo, 2012. p. 253-275.

LOSURDO. D. Contra-história do liberalismo. São Paulo, SP: Ideias \& Letras, 2006.

MACPHERSON, C. B. A democracia liberal: origens e evolução. Rio de Janeiro, RJ: Zahar, 1978.

MAGALHAES, F. 10 lições sobre Marx. Petrópolis, RJ: VOZES, 2014.

MARX, K.; ENGELS, F. Manifesto do partido comunista. In: BOGO, A. (Org.). Teoria da organização política. São Paulo, SP: Expressão Popular, 2010. p. 83-126.

MOÇAMBIQUE. Resolução n. 8, de 25 de agosto de 1988. Ratifica as Leis n. 1, 2, 3 e 4/88, respectivamente de 29 de janeiro e 12 de maio. Maputo, 25 ago. 1988. Disponível em: https://gazettes.africa/archive/mz/1988/mz-government-gazette-series-i-supplement-no-2dated-1988-08-25-no-34.pdf. Acesso 19 set. 2015.

MOÇAMBIQUE. Resolução n. 5, de 12 de dezembro de 1991. Ratifica o Pacto Internacional sobre Direitos Civis e Políticos, adoptado pela Assembleia Geral das Nações Unidas, em 16 de dezembro de 1966. Maputo, 12 dez. 1991a. Disponível em:

https:/gazettes.africa/gazettes/mz-government-gazette-series-i-supplement-dated-1991-12-12no-50\#: :text $=\% \mathrm{C} 2 \% \mathrm{~B} 0 \% 205 \% 2 \mathrm{~F} 91 \% 3 \mathrm{~A} \% 20 \mathrm{Considerando} \% 20$ que, $\operatorname{dos} \% 20$ seus $\% 20 \mathrm{em}$ $\% 2016 \% 20$ de. Acesso 19 set. 2015.

MOÇAMBIQUE. Resolução n. 6, de 12 de dezembro de 1991. Ratifica o Segundo Protocolo Adicional ao Pacto Internacional sobre os Direitos Civis e Políticos com vista a Abolição da Pena de Morte. Maputo, 12 dez. 1991b. Disponível em:

https:/gazettes.africa/gazettes/mz-government-gazette-series-i-supplement-dated-1991-12-12no-50\#: :text=\%C2\%B0\%205\%2F91\%3A\%20Considerando $\% 20$ que, dos $\% 20$ seus $\% 20 \mathrm{em}$ $\% 2016 \% 20$ de. Acesso 19 set. 2015.

MOÇAMBIQUE. Resolução n. 4, de 09 de junho de 1993. Reconhece o direito a pensão de aposentação previsto no artigo 258 do Estatuto Geral dos Funcionários do Estado aos funcionários sujeitos a aposentação obrigatória nos termos do n. 3 do artigo 257 do mesmo Estatuto. Maputo, 09 jun. 1993. Disponível em: https://gazettes.africa/archive/mz/1993/mzgovernment-gazette-series-i-dated-1993-06-09-no-23.pdf. Acesso 19 set. 2015.

MOÇAMBIQUE. Constituição da República Popular de Moçambique 2004. Maputo, 21 jan. 2005. Disponível em: http://www.

portaldogoverno.gov.mz/Legisla/constituicao_republica/constituicao.pdf. Acesso em: 12 mar. 2015.

PEREIRA, S. M. Educação Básica e formação docente no contexto das exigências do mundo do trabalho: a formação por competências em análise. Revista Cadernos de Educação, Pelotas (RS), n. 33, p. 57-79, maio/ago. 2009. 
SOUZA, D. D. L. Movimentos sociais, ONGs \& Educação. São Paulo, SP: Ideias \& Letras, 2009.

WOOD, E. M. Democracia contra capitalismo. São Paulo, SP: Boitempo, 2005.

WOOLF, A. Uma nova história do mundo. São Paulo, SP: mBooks, 2014.

\section{Como referenciar este artigo}

DOMINGOS, A. B.; PEREIRA, S. M. A igualdade de oportunidades educativas como pressuposto da democracia e as contradições na gestão democrática. Revista on line de Política e Gestão Educacional, Araraquara, v. 25, n. 3, p. 2710-2730, set./dez. 2021. eISSN:1519-9029. DOI: https://doi.org/10.22633/rpge.v25i3.14478

Submetido em: $20 / 08 / 2021$

Revisões requeridas em: 28/09/2021

Aprovado em: $17 / 10 / 2021$

Publicado em: 08/12/2021 